\title{
Stochastic Reservoir Systems with Different Assumptions for Storage Losses
}

\author{
Carter Browning1, Hillel Kumin ${ }^{2}$ \\ ${ }^{1}$ Halliburton Drill Bits and Services, Oklahoma City, OK, USA \\ ${ }^{2}$ School of Industrial and Systems Engineering, University of Oklahoma, Norman, OK, USA \\ Email: carter.browning@halliburton.com, hkumin@ou.edu
}

How to cite this paper: Browning, C. and Kumin, H. (2016) Stochastic Reservoir Systems with Different Assumptions for Storage Losses. American Journal of Operations Research, 6, 414-423.

http://dx.doi.org/10.4236/ajor.2016.65038

Received: August 15, 2016

Accepted: September 25, 2016

Published: September 28, 2016

Copyright $\odot 2016$ by authors and Scientific Research Publishing Inc. This work is licensed under the Creative Commons Attribution International License (CC BY 4.0).

http://creativecommons.org/licenses/by/4.0/

\begin{abstract}
Moran considered a dam whose inflow in a given interval of time is a continuous random variable. He then developed integral equations for the probabilities of emptiness and overflow. These equations are difficult to solve numerically; thus, approximations have been proposed that discretize the input. In this paper, extensions are considered for storage systems with different assumptions for storage losses. We also develop discrete approximations for the probabilities of emptiness and overflow.
\end{abstract}

\section{Keywords}

Stochastic Storage Systems, Storage Losses, Probability of Emptiness and Overflow

\section{Introduction}

Moran [1] [2], Prabhu [3] [4] and Ghosal [5] all considered a finite dam whose input in a given interval of time is a continuous random variable. Integral equations are then developed that give the probability of emptiness and overflow. It is difficult to obtain exact numerical results from these equations. An analytic solution has only been obtained for an Erlang input. Klemes [6], Lochert and Phatarfod [7], Phatarfod and Srikanthan [8] and others have obtained approximations for these probabilities by discretizing the input. Following Bae and Devine [9], we consider reservoir systems with different assumptions for storage losses. We then obtain integral equations as above for the probability of emptiness and overflow, and develop discrete approximations to obtain numerical results for the probabilities of overflow and emptiness.

Moran considered a storage model of a dam in discrete time, $t=0,1,2, \cdots$. Let $Z_{t}$ be the level of the dam before input $X_{t}$, where the X's are i.i.d. random variables. Let 
$Y_{t}$ be the release at the end of the time period $(t, t+1)$, where the Y's are i.i.d. random variables independent of the $X$ s, and let $k<\infty$ be the capacity of the system. If $Z_{t}+X_{t}>k$, then there is an overflow of $X_{t}+Z_{t}-k$. If $Z_{t}+X_{t} \leq k$ then no overflow occurs. At the end of the period, if there is an overflow, then $Z_{t+1}=k-Y_{t}$. If there is no overflow, then either $Z_{t+1}=Z_{t}+X_{t}-Y_{t}$ or $Z_{t+1}=0$ if the storage system is empty.

Lindley [10] showed that if certain independence conditions are satisfied then

$$
\begin{aligned}
F_{t+1}(y) & =\operatorname{Pr}\left\{\text { storage level } Z_{t+1} \text { of }(t+1)^{s t} \text { period } \leq y\right\} \\
& =\operatorname{Pr}\left\{Z_{t+1}=0\right\}+\operatorname{Pr}\left\{0<Z_{t+1} \leq y\right\} \\
& =\operatorname{Pr}\left\{Z_{t}+X_{t}-Y_{t} \leq 0\right\}+\operatorname{Pr}\left\{0<Z_{t}+X_{t}-Y_{t} \leq y\right\} \\
& =\operatorname{Pr}\left\{Z_{t}+X_{t}-Y_{t} \leq y\right\} .
\end{aligned}
$$

where $y \in[0, k]$. Further, define $H(\cdot)$ to be the c.d.f. of $U_{t}$ where

$$
U_{t}=X_{t}-Y_{t}
$$

Then, by convolution

$$
F_{t+1}(y)=\int_{-\infty}^{y} F_{t}(y-x) \mathrm{d} H(x), \quad 0 \leq y<\infty
$$

Since the limiting distribution $F(y)$ of $Z_{t}$ is independent of time $t$ in the steady state, for the semi-infinite case (bounded below), we have:

$$
F(y)= \begin{cases}\int_{0^{-}}^{\infty} F(y-x) \mathrm{d} H(x) & \text { if } y \geq 0 \\ 0 & \text { if } y<0\end{cases}
$$

which is equal to

$$
F(y)=-\int_{0^{-}}^{\infty} F(x) \mathrm{d} H(y-x), \quad y \geq 0
$$

Equations (1) and (2) are known as Lindley's equations. Numerical solutions for specific input distributions to Lindley's equations are difficult to obtain. In Moran's original work, a solution for exponential inputs was found, but was strictly limited to that distribution.

It is not an easy task to obtain probabilities for emptiness and overflow in continuous time. In this regard. Moran [6] proposed a discrete approximation in order to obtain numerical results for the probabilies of emptiness and overflow. Modifications to this approach have been developed by Klemes [3], Lochert and Phatarfod [5], Phatarfod and Srikanthan [8]. In this paper, we model energy storage systems with different assumptions about storage losses, and develop similar discrete approximations to calculate the probabilities of emtiness and overflow.

\section{Finite Model}

Moran's model yields the following Markov chain:

$$
Z_{t+1}= \begin{cases}0 & \text { if } Z_{t}+X_{t} \leq Y_{t} \\ Z_{t}+X_{t}-Y_{t} & \text { if } Y_{t}<Z_{t}+X_{t}<k \\ k-Y_{t} & \text { if } Z_{t}+X_{t} \geq k\end{cases}
$$


For the case of a finite system of capacity $k<\infty, F(y)=1$ for $y \geq k$ and Equation (2) becomes:

$$
\begin{aligned}
& F(y)=-\int_{0}^{k} F(x) \mathrm{d} H(y-x)-\int_{k}^{\infty} \mathrm{d} H(y-x) \\
& =H(y-k)-\int_{0}^{k} F(x) \mathrm{d} H(y-x) \quad 0 \leq y \leq k
\end{aligned}
$$

If the system has a constant release, then $Y_{t}=m<k$ and

$$
Z_{t+1}= \begin{cases}0 & \text { if } Z_{t}+X_{t} \leq m \\ Z_{t}+X_{t}-m & \text { if } m<Z_{t}+X_{t}<k \\ k-m & \text { if } Z_{t}+X_{t} \geq k\end{cases}
$$

Thus, $Z_{t+1}=\min \left\{k-m, \max \left[0, Z_{t}+X_{t}-m\right]\right\}$. Figure 1 illustrates a single time period of the previous Markov chain:

Now, let $G($.$) be the c.d.f. of X_{t}$, then

$$
H(u)=\operatorname{Pr}\left\{X_{t}-Y_{t} \leq u\right\}=\operatorname{Pr}\left\{X_{t}-m \leq u\right\}=G(u+m)
$$

Since $F(x)=1$ for $x \geq k-m$, Equation (3) becomes

$$
\begin{aligned}
F(y) & =-\int_{0}^{\infty} F(x) \mathrm{d} G(y-x+m) \\
& =-\int_{0}^{k-m} F(x) \mathrm{d} G(y-x+m)-\int_{k-m}^{\infty} \mathrm{d} G(y-x+m) \\
& =G(y+2 m-k)-\int_{0}^{k-m} F(x) \mathrm{d} G(y-x+m), \quad 0 \leq y \leq k-m
\end{aligned}
$$

\section{Losses from Storage}

\section{Model 1}

The most basic case of leakage occurs when a fixed amount $q$ leaks from storage after the release $Y_{t}$ at the end of each time interval. This type of system is shown below in Figure 2: (see Bae and Devine [9]):

Then, we have

$$
\operatorname{Pr}\left\{Z_{t+1} \leq y\right\}=\operatorname{Pr}\left\{Z_{t}+X_{t}-Y_{t}-q \leq y\right\}
$$

And

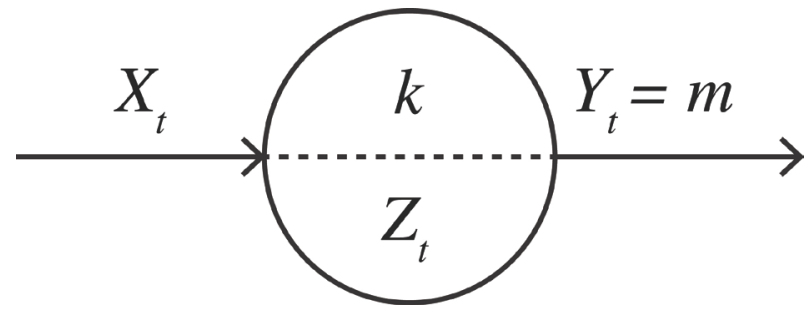

Figure 1. Simple storage system. 


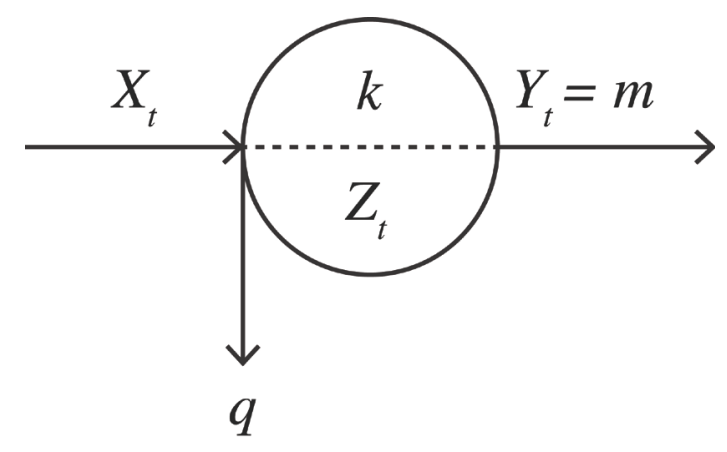

Figure 2. Fixed leakage from storage.

$$
\begin{aligned}
F(y) & =-\int_{0}^{\infty} F(x) \mathrm{d} H(y+q-x), \quad y \geq 0 \\
& =-\int_{0}^{k-q} F(x) \mathrm{d} H(y+q-x)-\int_{k-q}^{\infty} F(x) \mathrm{d} H(y+q-x) \\
& =H(y+2 q-k)-\int_{0}^{k-q} F(x) \mathrm{d} H(y+q-x)
\end{aligned}
$$

When the output is fixed, i.e., $Y_{t}=m$, define $U_{t}=X_{t}-(m+q)$. Applying this to the previous equation gives

$$
F(y)=G[y-k+2(m+q)]-\int_{0}^{k-m-q} F(x) \mathrm{d} G(y-x+m+q)
$$

Equations (5) and (6) indicate that leakage may be treated as a part of the output; thus, no separate analysis is needed in this case.

The second case represents a variable leakage whereby a quantity proportional to the amount stored is lost at the beginning of each time interval. Let $1-e_{0}$ denote the fraction of $Z_{t}$ lost in each period (i.e., $e_{0}$ is a measure of the storage efficiency). The Markov chain corresponding to this case is

$$
Z_{t+1}= \begin{cases}0 & \text { if } e_{0} Z_{t}+X_{t} \leq Y_{t} \\ e_{0} Z_{t}+X_{t}-Y_{t} & \text { if } Y_{t} \leq e_{0} Z_{t}+X_{t}<k \\ k-Y_{t} & \text { if } e_{0} Z_{t}+X_{t} \geq k\end{cases}
$$

Figure 3 illustrates this type of system:

$$
\begin{aligned}
F_{t+1}(y) & =\operatorname{Pr}\left\{e_{0} Z_{t}+X_{t}-Y_{t} \leq y\right\} \\
& =\int_{0}^{\infty} \operatorname{Pr}\left\{X_{t}-Y_{t} \leq y-e_{0} x \mid Z_{t}=x\right\} \operatorname{Pr}\left\{Z_{t}=x\right\} \\
& =\int_{0}^{\infty} H_{t}\left(y-e_{0} x\right) \mathrm{d} F_{t}(x)
\end{aligned}
$$

We thus have

$$
F(y)=H\left(y-e_{0} k\right)-\int_{0}^{k} F(x) \mathrm{d} H\left(y-e_{0} x\right)
$$




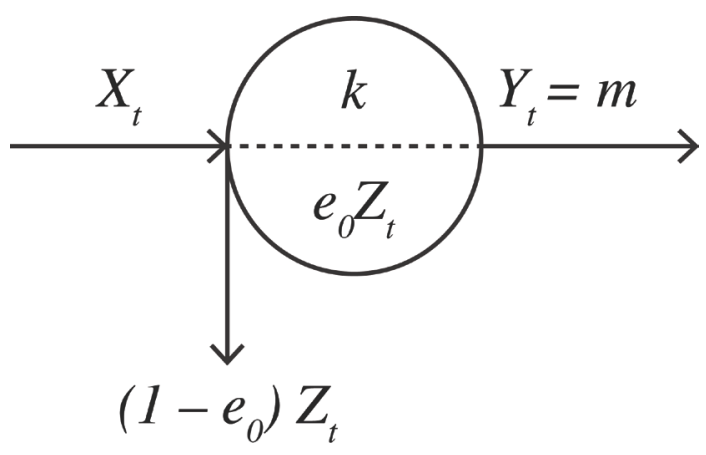

Figure 3. Fixed leakage from storage.

When the output is fixed, i.e., $Y_{t}=m$, we again have $F(x)=1$ for $x \geq k-m$. Then, the limiting c.d.f. of $Z_{t}$ is given by

$$
F(y)=G\left[y-e_{0} k+\left(1+e_{0}\right) m\right]-\int_{0}^{k-m} F(x) \mathrm{d} G\left(y-e_{0} x+m\right)
$$

\section{Model 2}

This model describes a system in which the input passes through a process having an efficiency $e_{1}$ before entering storage, and the quantity released from storage passes through an output process having an efficiency $e_{2}$ before leaving the system. The inputs $X_{t}$ are independent random variables following a given c.d.f. and each $Y_{t}=m$. A diagram of this system is given in Figure 4.

Now we define

$$
\begin{aligned}
& S_{t}= \begin{cases}X_{t}-m & \text { if } X_{t} \geq m \\
0 & \text { otherwise }\end{cases} \\
& T_{i}= \begin{cases}m-X_{t} & \text { if } X_{t}<m \\
0 & \text { otherwise }\end{cases}
\end{aligned}
$$

When both the input and output devices have efficiency factors, the schematic changes to (Figure 5).

It is apparent from (9) and (10) that either $S_{t}^{\prime}=e_{1} S_{t}$ or $T_{t}^{\prime}=\frac{T_{t}}{e_{2}}$ must be 0.

Similar to previous models, we also define

$$
\begin{aligned}
& G(\cdot)=\text { the c.d.f. of } X_{t} \\
& \hat{U}_{t}=S_{t}^{\prime}-T_{t}^{\prime} \\
& H(\cdot)=\text { the c.d.f. of } \hat{U}_{t}
\end{aligned}
$$

$\hat{H}(u)$ and $G(\cdot)$ are then given by

$$
H(u)=\left\{\begin{array}{ll}
G\left(\frac{u}{e_{1}}+m\right) & \text { if } u \geq 0 \\
G\left(e_{2} u+m\right) & \text { if } u<0
\end{array}= \begin{cases}\hat{H}\left(e_{1} u\right) & \text { if } u \geq 0 \\
\hat{H}\left(\frac{u}{e_{2}}\right) & \text { if } u<0\end{cases}\right.
$$

As before, 


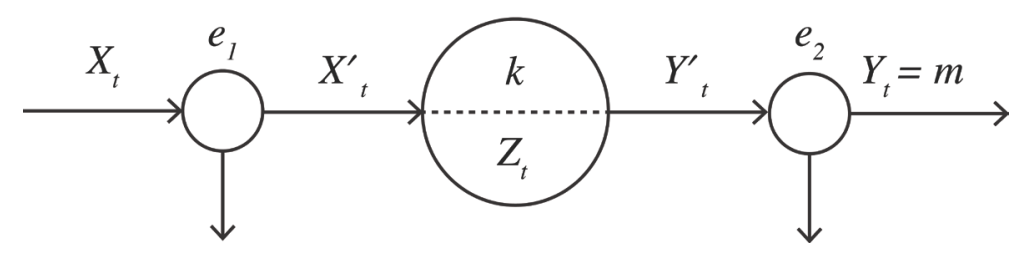

Figure 4. Input and output efficiencies.

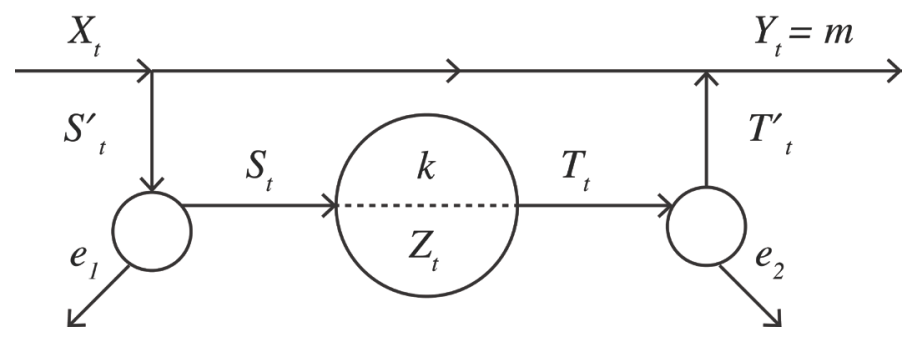

Figure 5. In-out devices efficiencies.

$$
\begin{aligned}
& F(y)=\lim _{t \rightarrow \infty} F_{t}(y)=-\int_{0}^{\infty} F(x) \mathrm{d} H(y-x) \\
= & H(y-k)-\int_{0}^{k} F(x) \mathrm{d} H(y-x), \quad 0 \leq y \leq k
\end{aligned}
$$

If

$$
\hat{H}(u)=\operatorname{Pr}\left\{S_{t}^{\prime}-T_{t}^{\prime} \leq u\right\}
$$

then

$$
\begin{aligned}
F(y) & =-\int_{0}^{\infty} F(x) \mathrm{d} \hat{H}(y-x) \\
& =-\int_{0}^{y} F(x) \mathrm{d} \hat{H}(y-x)-\int_{y}^{k} F(x) \mathrm{d} \hat{H}(y-x)-\int_{k}^{\infty} F(x) \mathrm{d} \hat{H}(y-x) \\
& =-\int_{0}^{y} F(x) \mathrm{d} \hat{H}(y-x)-\int_{y}^{k} F(x) \mathrm{d} \hat{H}(y-x)-\lim _{N \rightarrow \infty} \int_{k}^{N} F(x) \mathrm{d} \hat{H}(y-x) \\
& =-\int_{0}^{y} F(x) \mathrm{d} \hat{H}(y-x)-\int_{y}^{k} F(x) \mathrm{d} \hat{H}(y-x)-\lim _{N \rightarrow \infty} \hat{H}(y-N)+\hat{H}(y-k) \\
& =\hat{H}(y-k)-\int_{0}^{y} F(x) \mathrm{d} \hat{H}(y-x)-\int_{y}^{k} F(x) \mathrm{d} \hat{H}(y-x) \\
& =H\left(y-\frac{k}{e_{2}}\right)-\int_{0}^{y} F(x) \mathrm{d} H\left(e_{1}(y-x)\right)-\int_{y}^{k} F(x) \mathrm{d} H\left(\frac{y-x}{e_{2}}\right) \\
& =G\left(y-\frac{k}{e_{2}}\right)-\int_{0}^{k} F(x) \mathrm{d} G\left(e_{1}(y-x)\right)-\int_{y} F(x) \mathrm{d} G\left(\frac{y-x}{e_{2}}\right)
\end{aligned}
$$

\section{Methodology}

We develop a discrete analogue by defining 


$$
\begin{gathered}
F_{i}=\operatorname{Pr}\left(Z_{t} \leq i\right) \\
g_{i}=\operatorname{Pr}\left(X_{t}=i\right) \\
G_{j}= \begin{cases}\sum_{i=0}^{j} g_{i} & \text { if } j \geq 0 \\
0 & \text { if } j<0\end{cases}
\end{gathered}
$$

Thus

$$
F_{i}= \begin{cases}0 & \text { if } i<0 \\ G_{i+2 m-k}+\sum_{j=0}^{k-m-1} g_{i+m-j} F_{j} & \text { if } i=0,1, \cdots, k-m-1 \\ 1 & \text { if } i \geq k-m\end{cases}
$$

where the probabilities of emptiness and overflow are

$$
\begin{gathered}
\operatorname{Pr}\{\text { emptiness }\}=\operatorname{Pr}\left\{Z_{t} \leq 0\right\}=F(0)=F_{0} \\
\operatorname{Pr}\{\text { overflow }\}=\operatorname{Pr}\left\{Z_{t} \geq k-m\right\}=1-F(k-m-1)=1-F_{k-m-1}
\end{gathered}
$$

\subsection{Fixed Leakage}

When the storage has a fixed quantity $q$ that leaks as given in Equations (5) and (6), the discrete analogue is given by

$$
F_{i}= \begin{cases}0 & \text { if } i<0 \\ G_{i+2(m-q)-k}+\sum_{j=0}^{k-m-q-1} g_{i+m+q-j} F_{j} & \text { if } i=0,1, \cdots, k-m-1 \\ 1 & \text { if } i \geq k-m\end{cases}
$$

where the probabilities of emptiness and overflow are

$$
\begin{gathered}
\operatorname{Pr}\{\text { emptiness }\}=\operatorname{Pr}\left\{Z_{t} \leq 0\right\}=F(0)=F_{0} \\
\operatorname{Pr}\{\text { overflow }\}=\operatorname{Pr}\left\{Z_{t} \geq k-m\right\}=1-F(k-m-1)=1-F_{k-m-1}
\end{gathered}
$$

\subsection{Storage Leakage}

A discrete analogue of (8) is

$$
F_{i}= \begin{cases}0 & \text { if } i<0 \\ G_{i+\left(1-e_{0}\right) m-e_{0} k}+\sum_{j=0}^{k-m-1} g_{i+m-e_{0} j} F_{j} & \text { if } i=0,1, \cdots, k-m-1 \\ 1 & \text { if } i \geq k-m\end{cases}
$$

where the probabilities of emptiness and overflow are

$$
\begin{gathered}
\operatorname{Pr}\{\text { emptiness }\}=\operatorname{Pr}\left\{Z_{t} \leq 0\right\}=F(0)=F_{0} \\
\operatorname{Pr}\{\text { overflow }\}=\operatorname{Pr}\left\{Z_{t} \geq k-m\right\}=1-F(k-m-1)=1-F_{k-m-1}
\end{gathered}
$$

\section{Constant Output Model}

Using the definitions (14)-(16), we have 


$$
F_{i}= \begin{cases}0 & \text { if } i<0 \\ G_{i+m-k}+\sum_{j=0}^{k-1} g_{i+m-j} F_{j} & \text { if } i=0,1, \cdots, k-1 \\ 1 & \text { if } i \geq k\end{cases}
$$

where the probabilities of emptiness and overflow are

$$
\begin{gathered}
\operatorname{Pr}\{\text { emptiness }\}=\operatorname{Pr}\left\{Z_{t} \leq 0\right\}=F(0)=F_{0} \\
\operatorname{Pr}\{\text { overflow }\}=\operatorname{Pr}\left\{Z_{t} \geq k\right\}=1-F(k-1)=1-F_{k-1}
\end{gathered}
$$

\section{Numerical Results}

Figure 6 and Figure 7 represent the impact of storage leakage on the basic system. The capacity of the following systems is determined in relation to the release amount. Figure 6 below gives the emptiness probabilities for an average input of 3.75 with a standard deviation of 1 , and a storage efficiency $e_{0}$, of $75 \%$.

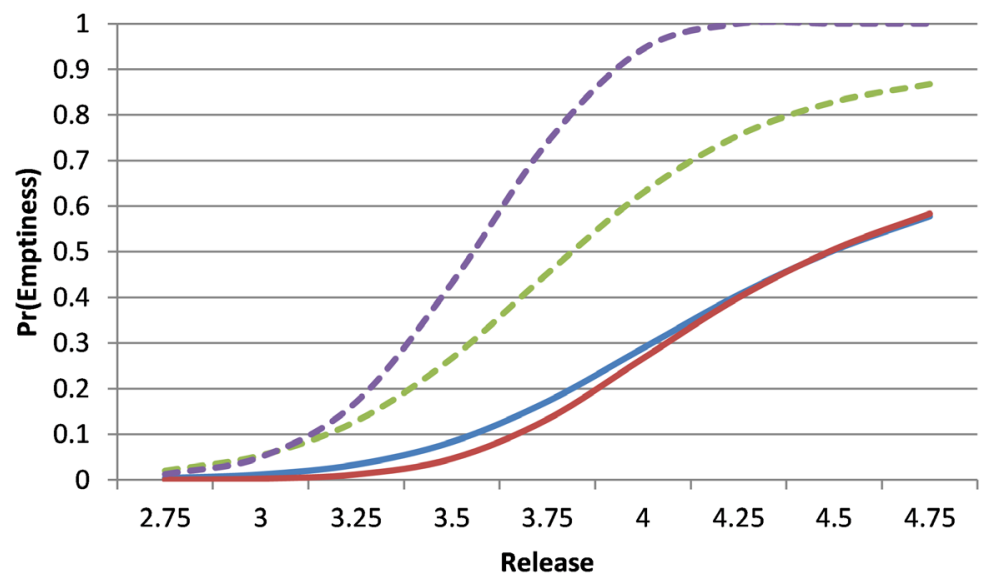

Simple System

K-M $=2$

$\mathrm{K}-\mathrm{M}=3$

Storage Leakage

$-\infty \mathrm{K}-\mathrm{M}=2$

$---K-M=3$

Figure 6. Comparative emptiness probabilities.

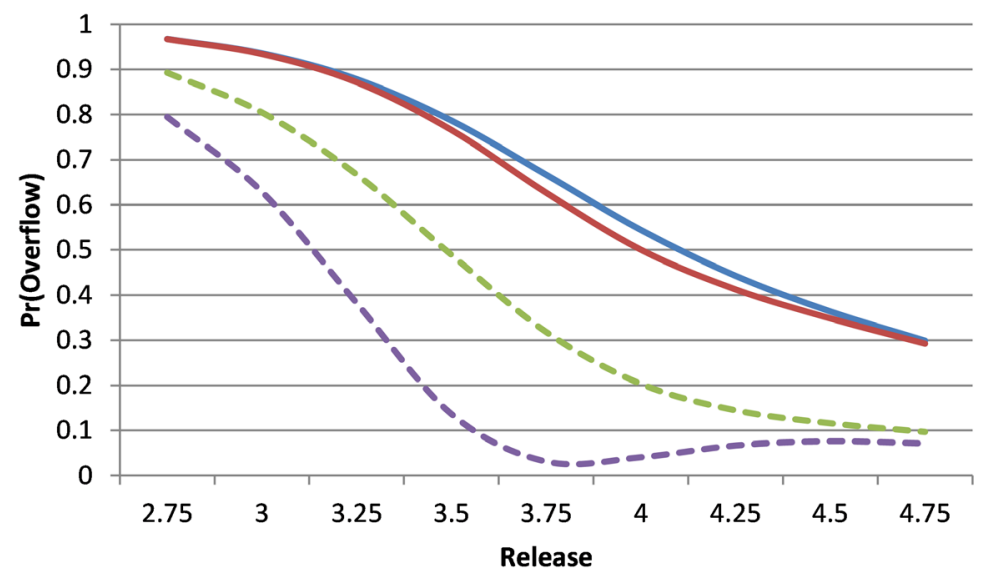

Simple System

$K-M=2$

$\mathrm{K}-\mathrm{M}=3$

Storage Leakage

$-\infty \mathrm{K}-\mathrm{M}=2$

$-\infty \mathrm{K}-\mathrm{M}=3$

Figure 7. Comparative overflow probabilities. 
Figure 8 represents the difference between Figure 6 and Figure 7. For both systems, there is an input of 4 , with a release between 2 and 10, and a capacity determined by the relation of $k-m=3$.

Figure 9 represents the impact of a varying standard deviation on an input.

In this system, the input is 15 , release is 15 , and capacity ranges from 17 to 26 . Additionally, each probability is determine with a standard deviation of $0.75,1,2$ and 4 .

Figure 10 represents the impacts of efficiency on the input and output process on the model obtained for the probability of overflow.

For this system, the input is 15 with a standard deviation of 4 . The capacity for this system is 30 . Additionally, the release changes from 7 to 21 . "Series 1 " has input/output efficiency of 1 , "Series 2 " has efficiency of $0.5 / 1$, "Series 3 " has efficiency of $1 / 0.5$, and "Series 4" has efficiency of 0.7/0.9.

\section{Sensitivity Analysis}

Figure 6 and Figure 7 represent the impact of storage leakage on the basic system

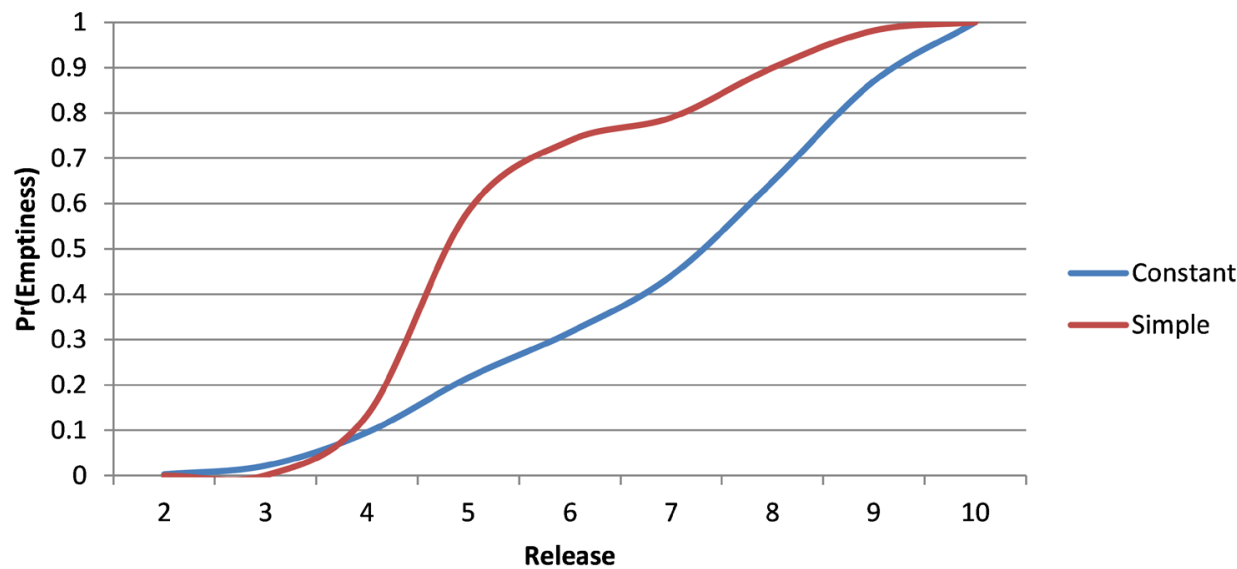

Figure 8. Comparative simple and constant output probabilities.

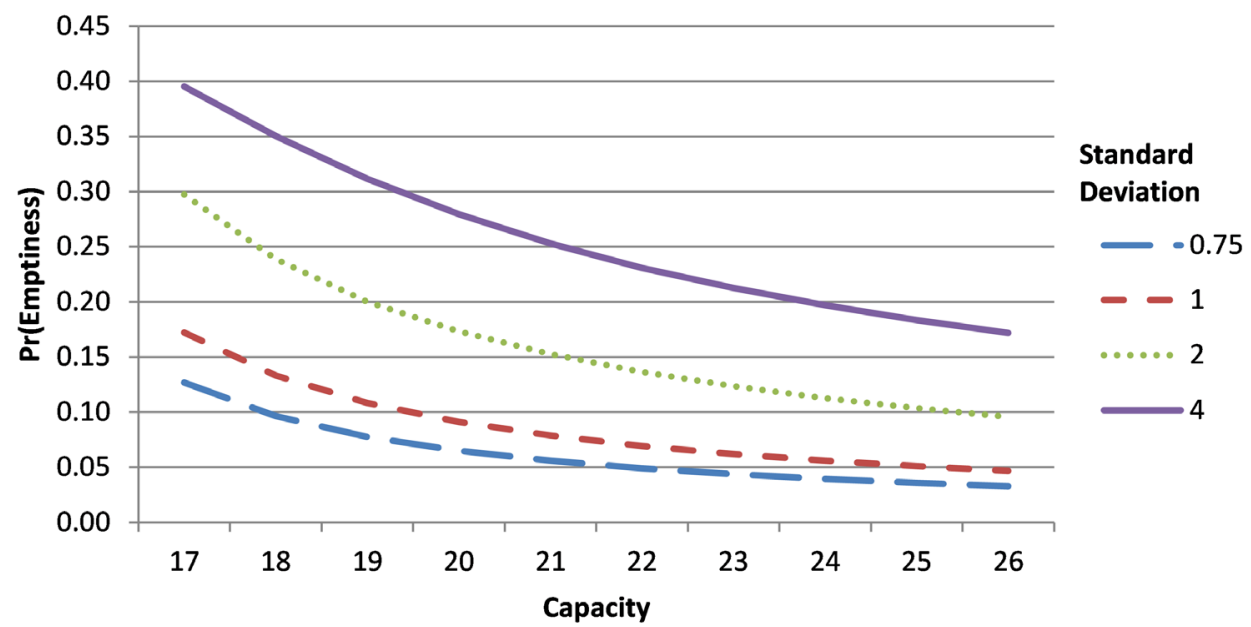

Figure 9. Represent the impact of a varying standard deviation on an input. 


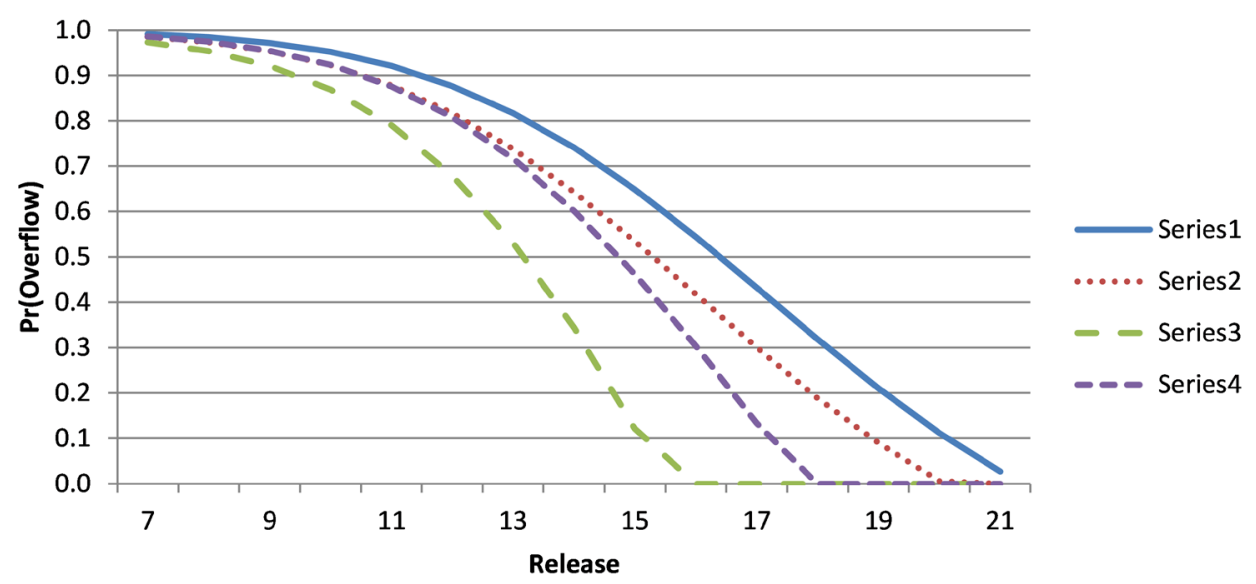

Figure 10. Impact of input/output efficiency.

when the basic discrete time model is considered. The capacity of the following system is determined in relation to the release amount. The input is 3.75 with a standard deviation of 1 , and a storage efficiency, $e_{0}$, of $75 \%$.

Figure 8 represents the difference between Figure 6 and Figure 7. For both systems, there is an input of 4 , with a release between 2 and 10, and a capacity determined by the relation of $k-m=3$.

\section{References}

[1] Moran, P.A.P. (1954) A Probability Theory of Dams and Storage Systems. Australian Journal of Applied Science, 5, 116-124.

[2] Moran, P.A.P. (1959) The Theory of Storage. Methuen and Co, London.

[3] Prabhu, N.U. (1958) Some Exact Results for the Finite Dam. Annals of Mathematical Statistics, 29, 1234-1243. http://dx.doi.org/10.1214/aoms/1177706454

[4] Prabhu, N.U. (1985) Stochastic Storage Processes: Queues, Insurance Risk, Dams, and Data Communication. Springer-Verlag, New York.

[5] Ghosal, A. (1969) Some Aspects of Queueing and Storage Systems. Lecture Notes in Operations Research and Mathematical Systems, No. 23, Springer-Verlag, New York.

[6] Klemes, V. (1977) Discrete Representation of Storage for Stochastic Reservoir Operation. Water Resources Research, 13, 149-158. http://dx.doi.org/10.1029/WR013i001p00149

[7] Lochert, P. and Phatarfod, R.M. (1979) On the Problem of Discretization in Dam Theory. Water Resources Research, 15, 1593-1597. http://dx.doi.org/10.1029/WR015i006p01593

[8] Phatarfod, R.M. and Shrikanthan, R. (1981) Discretization in Stochastic Reservoir Theory with Markovian Inflows .Journal of Hydrology, 52, 199-218.

http://dx.doi.org/10.1016/0022-1694(81)90170-0

[9] Bae, H.M. and Devine, M. (1978) Optimization Models for the Economic Design of Windpower Systems. Solar Energy, 20, 469-481. http://dx.doi.org/10.1016/0038-092X(78)90064-6

[10] Lindley, D.V. (1952) The Theory of Queues with a Single Server. Mathematical Proceedings of the Cambridge Philosophical Society, 48, 277-289. http://dx.doi.org/10.1017/S0305004100027638 
Submit or recommend next manuscript to SCIRP and we will provide best service for you:

Accepting pre-submission inquiries through Email, Facebook, LinkedIn, Twitter, etc. A wide selection of journals (inclusive of 9 subjects, more than 200 journals)

Providing 24-hour high-quality service

User-friendly online submission system

Fair and swift peer-review system

Efficient typesetting and proofreading procedure

Display of the result of downloads and visits, as well as the number of cited articles

Maximum dissemination of your research work

Submit your manuscript at: http://papersubmission.scirp.org/

Or contact ajor@scirp.org 